\title{
The Examination of the Relationship between Left-Handedness and Success in Elite Female Archers
}

\author{
Recep Gursoy${ }^{1}$, Suleyman Sahin², Mehmet Dalli³, Kursat Hazar4, Eser Aggon ${ }^{5}$ \\ ${ }^{1}$ Faculty of Sports Sciences, Mugla Sitki Kocman University, Mugla, Turkey \\ ${ }^{2}$ Youth Services and Sports Provincial Directorate, Bursa, Turkey \\ ${ }^{3}$ Faculty of Sports Sciences, Mugla Sitki Kocman University, Mugla, Turkey \\ ${ }^{4}$ Department of Physical Education, Mugla Sitki Kocman University, Mugla, Turkey \\ ${ }^{5}$ Department of Physical Education, Erzincan University, Erzincan, Turkey \\ Email: recepgursoy@mu.edu.tr
}

How to cite this paper: Gursoy, R., Sahin, S., Dalli, M., Hazar, K., \& Aggon, E. (2017). The Examination of the Relationship between Left-Handedness and Success in Elite Female Archers. Advances in Physical Education, 7, 367-376.

https://doi.org/10.4236/ape.2017.74030

Received: April 26, 2017

Accepted: September 26, 2017

Published: September 29, 2017

Copyright () 2017 by authors and Scientific Research Publishing Inc. This work is licensed under the Creative Commons Attribution International License (CC BY 4.0).

http://creativecommons.org/licenses/by/4.0/

\begin{abstract}
Objective: This research was carried out in order to determine the hand and eye dominance (left-hand dominant or right-hand dominant) of the women participating in Turkish senior women's archery championship and to find out whether there were any differences among the scores gained by the archers as general total and at the end of their $1^{\text {st }}$ and $2^{\text {nd }} 50-\mathrm{m}$ target-based shootings when using compound bow. Method: 44 elite-level women archers under the Turkish Federation of Archery participated in the research. We determined the hand dominance and eye dominance of all participants. To determine hand and eye dominance, participants completed the Edinburgh Handedness Inventory-Short Form. According to that, 5 of the archers were left-hand dominant whereas 39 of them were right-hand dominant. A mini survey form was used in order to determine certain bio-motor (age, height, weight and sports age) characteristics of the archers. Results: Laterality might be one of the most significant factors for the archers to become successful. Thus, considering that left-hand dominant archers might gain competitive edge in the archer selection process, these archers can be considered to be advantageous for being selected. Sportive success can be enhanced if trainers attach a particular importance to and support these archers and if they consider this situation particularly during target-based shooting trainings. Furthermore, taking into consideration that left-hand dominant persons are more successful that right-hand dominant persons in certain sports branches, it can be said that, such persons must not be forced to use their right hand.
\end{abstract}




\section{Keywords}

Hand Preference, Archer, Sports

\section{Introduction}

Handedness is the tendency of humans to use, in various movements or motor tasks, one hand rather than the other (Lanzoni et al., 2013). The topic of handedness has received a lot of attention in several research fields. It is well known that left-handers are a minority of the general population: their proportion is normally reported to range, with some cultural variations, between $10 \%$ and 13\% (Raymond et al., 1996; Shorer et al., 2012). Interestingly, the proportion of left-handed individuals seems not to have changed since the Paleolithic age (Faurie \& Raymond, 2005), although handedness has both a genetic and environmental origin (Steele \& Umini, 2005), and left-handedness is associated to fitness costs and functional disadvantages (Geschwin \& Behan, 1982; Donaldson \& Johnson, 2006). Therefore, it can be supposed that left-handers have also some advantages when compared to right-handers. For example, a selection mechanism linked to fighting interactions has been suggested (Raymond et al., 1996). About 90 percent of all humans are right-handed, the left-brain dominates for motor skills because the vast majority of people are right-handed, (Coon \& Mitterer, 2011). Right hands often show performance differences that have been attributed to hemispheric specialization. The right hemisphere is superior at imagery and visual abilities, therefore lefties are better at visualization In general, left-handers are more symmetrical on almost everything including eye dominance, fingerprints, (Coon \& Mitterer, 2009). A number of studies have investigated handedness differences and suggested that left-handed players have probably an intrinsic neurological advantage (Eckner et al., 2010). Loffing et al. (2010) reported left-handers were found with disproportionately more frequency in interactive sports such as tennis, fencing. Left-handers' performance advantage persists in amateur tennis. In general, the advantage of left-handers in fights may be reflected in a sport context, especially in combat sports (e.g., boxing, judo and karate), interactive team sports (e.g., rugby and handball), and racket sports (e.g., table tennis and badminton) (Raymond et al., 1996). Some authors hypothesized a neuropsychological advantage of left-handed sportsmen (Annett, 1985; Nass \& Gazzaniga, 1987). However, (Wood \& Aggleton, 1989) observing in fast ball sports a proportion of left-handed players higher than in the general population, concluded that the advantage of left-handers was due to specific characteristics of the sports disciplines rather than to neuropsychological factors. Additionally, it has been reported that there is a high proportion of left-handedness among top athletes in baseball (Fisekcioglu, 2011), in tennis (Holtzen, 2000), in fencing (Bisiacchi et al., 1985), in cricket (Wood \& Aggleton, 1989). Therefore, it can be expected some relationships 
between hand pereference and succes in archery. The research carried out within the framework of the above-mentioned information has three objectives. The first of these is to determine hand and eye dominance of the women archers participating in Turkish archery championship; the second is to find out whether the scores gained as general total and at the end of first and second 50-m target-based shootings of the archers have influence on success in sports; and third, to help the trainers and beginner archers in parallel with the above-given information about the hand and eye dominance when selecting the archers.

\section{Material and Method}

This research was carried out to analyze the left-hand dominant and right-hand dominant women archers under the Turkish Federation of Archery, who participated in the Turkish senior women's archery championship in order to find out whether there were any differences among the scores gained by the archers as general total and at the end of their $1^{\text {st }}$ and $2^{\text {nd }} 50$ - $\mathrm{m}$ target-based shootings when using compound bow, with respect to their hand dominance. 44 elite-level women archers under the Turkish Federation of Archery participated in the research.

To determine the hand preference of the archers Oldfield (1971) (Edinburg Handedness Inventory) survey form was used. 10 questions were included in the survey form. These questions aimed to find out which hand was used for: 1) writing; 2) drawing picture; 3) throwing a ball or a stone; 4) holding scissors; 5) brushing teeth; 6) holding a knife without forks; 7) holding forks; 8) holding a shovel; 9) striking a match; and 10) opening the cap of a bottle. The options were; "always the right hand" (+10 points), "mostly the right hand" (+5 points), "both hands" ( 0 point), "mostly the left hand" ( -5 points) and "always the left hand" $(-10$ points). The total of the above-given points gives the laterality score. Distribution of the scores was as the following: Strongly right-hand dominant persons were scored between +80 and +100 points and the strongly left-hand dominant persons were scored between -80 and -100 points. 5 of the archers were left-hand dominant whereas 39 of them were right-hand dominant. The keyhole test included in the same test was applied in order to determine eye dominance.

\subsection{Participants}

Forty-four elite level female archers (the age average of the archers was $22.84 \pm$ 2.41; height average was $165.48 \pm 5.84$; weight average was $64.04 \pm 5.42$ and sports age average was $5.34 \pm 1.31$.) within the Turkish Archery Federation program participated to the study.

\subsection{Experimental Design and Procedures}

In shooting analysis, the archers shot 6 arrows for the $1^{\text {st }}$ and $2^{\text {nd }} 50-\mathrm{m}$ target-based shootings in a contest according to the official rules of the international federation of archery. They repeated these shootings for two times and com- 
pleted their shootings with 6 arrow shootings in series of 6 for each repetition $(2 \times$ $36=72$ arrow shootings). In the contest, the archers received 10 points for each arrow hitting the target and the scoring went as $9,8,7,6$ and 5 toward the lower targets and the general total was calculated as $10 \times 72=720$.

\subsection{Statistical Analysis}

Descriptive statistics was used in the assessment of the scores of the archers for the two 50-m target-based shootings and the group variables were determined. Independent sample $t$ test at significance level of 0.05 was used in order to determine the difference between the group variable data averages. Correlation analysis at a significance level of 0.05 was used in order to determine the correlation between the variables, the power and direction of the correlation.

\section{Results}

Table 1 shows that the age average of the archers was $22.84 \pm 2.41$; height average was $165.48 \mathrm{sd} \pm 5.84$; weight average was $64.04 \pm 5.42$ and sports age average was $5.34 \pm 1.31$. Scores for the first 50 - $\mathrm{m}$ shootings of the archers were between 135 and $344 ; \mu=284.36 \pm 50.12$. Scores for the second 50-m shootings were between 131 and $155 ; \mu=289.30 \pm 52.72$. Their total scores were measured as $289-695 ; \mu=$ $574.09 \pm 100.06$.

As can be understood from the Table 2, average general total scores and the first and second 50-m shooting scores the left-hand dominant archers achieved in their right-hand, target-based shootings using roller arrow were higher compared to those achieved by the right-hand dominant archers using their right hand. On the other hand, assessment of the total scores with respect to the range showed that the ranges of the first and second 50-m shootings standard deviations of the left-hand dominant archers were narrower compared to the right-hand dominant archers. In other words; the first and second 50-m shooting scores of the left-hand dominant archers did not change significantly.

As can be seen in Table 3, 5 of the archers were left-hand dominant whereas 39 of them were right-hand dominant and used their right hand to shoot the arrow. Left-hand dominant archers had an average score of $334.80 \mathrm{sd} \pm 6.87$ in

Table 1. Descriptive statistics.

\begin{tabular}{cccccc}
\hline Changeables & $\mathbf{n}$ & minimum & maximum & mean & sd \\
\hline Age & 44 & 18 & 30 & 22.84 & 2.41 \\
Height & 44 & 154 & 176 & 165.48 & 5.84 \\
Weight & 44 & 56 & 74 & 64.04 & 5.42 \\
Sport age & 44 & 3 & 8 & 5.34 & 1.31 \\
First (50 m) & 44 & 135 & 344 & 284.36 & 50.12 \\
Second (50 m) & 44 & 131 & 351 & 289.30 & 52.72 \\
Total & 44 & 289 & 695 & 574.09 & 100.06 \\
The number of arrows & 44 & 72 & 72 & 72.00 & \\
\hline
\end{tabular}


Table 2. Test of normality.

\begin{tabular}{cccc}
\hline & \multicolumn{3}{c}{ Kolmogorov-Smirnov } \\
\cline { 2 - 4 } & statistic & $\mathrm{df}$ & $p$ \\
\hline First $(50 \mathrm{~m})$ & 0.100 & 44 & 0.60 \\
Second $(50 \mathrm{~m})$ & 0.100 & 44 & 0.51 \\
Total & 0.185 & 44 & 0.52 \\
\hline
\end{tabular}

First $(50 \mathrm{~m})$, second $(50 \mathrm{~m})$ and total scores show normal distribution $(p>0.05)$.

Table 3. Group statistics.

\begin{tabular}{ccccc}
\hline \multicolumn{2}{c}{ The hands dominant of archers } & $\mathrm{n}$ & mean & sd \\
\hline \multirow{2}{*}{ First $(50 \mathrm{~m})$} & Left hand & 5 & 334.80 & 6.87 \\
& Right hand & 39 & 227.90 & 49.60 \\
\multirow{2}{*}{ Second $(50 \mathrm{~m})$} & Left hand & 5 & 335.80 & 8.76 \\
& Right hand & 39 & 283.33 & 53.06 \\
\multirow{2}{*}{ Total } & Left hand & 5 & 670.60 & 14.12 \\
& Right hand & 39 & 561.72 & 99.63 \\
\hline
\end{tabular}

their first right-hand 50-m shooting whereas right-hand dominant archers had an average score of $227.90 \pm 49.60$ in their first right-hand 50 -m shooting. Left-hand dominant archers scored $335.80 \pm 8.76$ on average, in their second $50-\mathrm{m}$ shooting whereas the right-hand dominant archers scored $283.33 \pm 53.06$ on average. Average total shooting score was $670.60 \pm 14.12$ on average, for the left-hand dominant archers, whereas it was $561.72 \pm 99.63$ on average, for the right-hand dominant archers.

Table 3 presents a significant difference $(p<0.05)$ between the first $50-\mathrm{m}$ target-based shootings of left- and right-hand dominant archers. Left-hand dominant archers scored $(\mu=334.80)$ more than the right-hand dominant archers $(\mu=$ $227.90)$ in their first 50-m shootings. There was a significant difference $(p<$ $0.05)$ between the average scores of the second 50-m target-based shootings of left- and right-hand dominant archers. Left-hand dominant archers scored $(\mu=$ 335.80) more than the right-hand dominant archers $(\mu=283.33)$ in their second $50-\mathrm{m}$ shootings. Average total scores of the target-based shootings of the left-hand dominant archers were significantly higher $(p<0.05)$ than the right-hand dominant archers. Left-hand dominant archers $(\mu=670.60)$ had a higher total score compared to right-hand dominant archers $(\mu=561.72)$.

As we can understand from the Table 4, the mean scores of the dominant left-handed archers from the shots they made by using the bow with left hand and arrow right hand to the target are higher than the mean scores of the dominant right-handed archers made by using the bow with right hand and arrow left hand to the target in the first and second $50 \mathrm{~m}$ shots and in general total. On the other hand, when the scores achieved in terms of change interval are examined, it is observed that the change intervals of the dominant left-handed archers are narrower in standard deviations of the first and second 50 meter shots compared 
Table 4. Independent samples t-test.

\begin{tabular}{cccc}
\hline Changeables & sd. & $\mathrm{t}$ & $p$ \\
\hline First $(50 \mathrm{~m})$ & 42 & 2.537 & 0.015 \\
Second $(50 \mathrm{~m})$ & 42 & 2.185 & 0.035 \\
Total & 42 & 2.146 & 0.020 \\
\hline
\end{tabular}

Table 5. The correlation between the archers' success in right-hand target-based shooting and their hand dominance.

\begin{tabular}{ccc}
\hline Dominant hands of archers & First $(50 \mathrm{~m})$ & Second $(50 \mathrm{~m})$ \\
\hline Pearson correlation & $-3.64^{\star}$ & $0.898^{\star *}$ \\
$P$ & 0.015 & 0.000 \\
$\mathrm{~N}$ & 44 & 44 \\
\hline
\end{tabular}

${ }^{\star} 0.05$ significance level; ${ }^{*} 0.01$ significance level.

to right-handed archers. In other words, there was not a very big change between the scores of the first and second 50 meter shots of left-handed archers.

When looking at In Table 5, left-hand dominant archers scored better in the 50-m target-based shootings when holding the bow with their right-hand compared to right-hand dominant archers. On the other hand, there was a weak negative correlation $(p<0.05)$ between the dominant hand and the success rating. Similar results were obtained at the end of the second $50-\mathrm{m}$ shootings. There was a significant positive correlation between the dominant hand and the success rating $(p<0.1)$. Left-hand dominant archers scored better in target-based shootings compared to right-hand dominant archers. This case was true both in the first and the second 50-m shootings. On the other hand, it was more obvious in the second $50-\mathrm{m}$ shootings.

\section{Discussion}

This research consists of three stages. The first one aims to apply the OldField (1971) (Edinburgh Handedness Inventory) test method to determine the hand and eye dominance in women archers; with the determination of the hand dominance of the women archers participating in the Turkish senior women's championship, the second stage aims to find out whether the first and second 50-m target-based shootings of the women archers have any influence on success in sports. The third stage aims to help the trainers, beginner archers and anyone interested in parallel with the available information about the hand and eye dominance when selecting the archers.

As already known, the ones with dominant hand also have the abilities to use hand and foot in a dominant manner and to hear and see better. Furthermore, as they actively use these organs in daily life and in sports activities, they develop much more than the non-dominant organs. There are recent researches that have been performed to analyze the correlation between hand dominance and success in sports. However, this might cause different reflection of the correla- 
tion between eye dominance and success of the archers.

Considering the target-based shootings performed with bow and arrow in archery, it can be said that the bow used is mostly developed in favor of the right-hand dominant persons, indeed. But left-hand dominant persons have to use them, too. Hence, archers shoot thousands or ten thousands of arrows using bows and develop their dominant extremity and sight functions. Still, this might cause problems for beginner archers when they need to see the target with their non-dominant eye and when they perform target-based shootings. Long-term trainings can eliminate this problem in time. Thus, non-dominant right eye of the left-hand dominant archers can improve sight throughout the years with target-based shootings. But this requires scientific studies. On the other hand, long-term trainings can further improve motor learning and skills with nerve and muscle coordination.

As is known, those who with dominant hand preferences at the same time have better hearing and vision skills in addition to dominant usage of hand and foot skills and the limbs used more effectively in daily life and sporting activities show a greater improvement than non-dominant limbs. There are some recent works as to relation of hand preference and success in sports. It has been suggested that left-handers have an intrinsic advantage over right-handers due to superior spatio-motor skills and that the relatively high proportion of this innate superiority (Annet, 1985; Geshwind \& Galburda, 1985). (Brooks et al., 2004) Also, analyzed the batting records from the 2003 cricket World Cup and showed that left-handed batsman were more succesfull than right-handers and that the most succesfull teams had close to \% 50 left-handed batsman. Considering sports like shooting, interaction between hand preference and eye dominance seems a relevant factor in performance (Shereran, 1985; Jones et al., 1996).

On the other hand, the rate of left-handedness was higher in wrestlers with medal honors compared to wrestlers without medals for both men and women. the winning numbers and match degrees were higher in the lef-handed wrestler than in both right-and mixed handed wrestlers in international top wrestlers. It has been suggested that left-handed wrestlers are more succesful (Gursoy et al., 2010). Left-handed boxers were found to be more successful than right-handed (Gursoy, 2009). Furthermore, study cited by Loffing et al. (2012) found that a left-handers' performance advantage persists in amateur tennis. The uncrossed eye-hand pattern is distinctly more succesful than the crossed eye-hand pattern, given the features of the activity, motionless target, and nonexistent time pressure. more over, to aim at the target to use the arm corresponding to the sighting eye. This presence of uncrossed patterns in sighting sports was reported by Porac and Coren (1981), who noted among the elite performances in these sports more uncrossed than crossed patterns. The difference in performance of each pattern can be explained by the different way used to transmit visual information. Archery requires more accuracy than speed, so it requires the intervention of the geniculate-striate system, which is the one used more often in 
the uncrossed pattern, contrary to the retinotectal system, which is used principally in situations with target motion and time pressure and which is used more often in crossed pattern (Azemar, 2003). In archery, the principal quality required is visuomotor coordination, which directly affects performance (Simon, 1998). However, this case may lead to different reflections of eye preference and achievement statues in those engaged with archery sports. The laterality used by some practitioners of archery. Some results are from those obtained in other sighting sports like pistol shooting or marksman sports, where uncrossed pattern was associate with elite practice status (Porac \& Coren, 1981).

When target shooting using bows and arrows archery are evaluated we see that the bow is generally a tool developed for the use of right-handed people. Much as this is the case, it is inevitable for left-handed people to use this equipment. Therefore, archers improve their dominant extremities and vision functions by shooting thousands of times with the bows and arrows they use over the years. This can be overcome by long-term training works in the following periods. In other words, the non-dominant right eyes of the lefties may gain better eyesight over time with the arrows shot to the target. However, scientific works are required on this field. On the other hand, long-term trainings can improve motor learning and ability in addition to nerve and muscle coordination (Sylvain \& Fabrice, 2009). Also, archery requires repetition of the same gesture many thousands of times, leading to automation. This maybe based on complex cognitive changes in the central nervous system. This process of motor learling may perhaps be associated with changes in laterality pattern (Peters, 2004).

\section{Conclusion}

In conclusion, laterality might be one of the most significant factors for the archers to become successful. Thus, considering that left-hand dominant archers might gain competitive edge in the archer selection process, these archers can be considered to be advantageous for being selected. Sportive success can be enhanced if the families are aware of this characteristic of their children, if trainers attach a particular importance to and support these archers and if they consider this situation particularly during target-based shooting trainings. Furthermore, taking into consideration that left-hand dominant persons are more successful than right-hand dominant persons in certain sports branches, it can be said that such persons must not be forced to use their right hand.

\section{References}

Annett, M. (1985). Left, Right, Hand and Brain: The Right Shift Theory. London: Erlbaum.

Azemar, G. (2003). L'Homme Asymetrique: Gauchers et Droitiers Face a Face. [Asymmetric Man: Left and Right Handed Face to Face.] Paris: CNRS.

https://doi.org/10.4000/books.editionscnrs.8714

Bisiacchi, P. S., Ripoll, H., Stein, J., Simonet, P., \& Azemar, G. (1985). Left-Handedness in 
Fencers: An Attentional Advantage? Perceptual and Motor Skills, 61, 507-513. https://doi.org/10.2466/pms.1985.61.2.507

Brooks, R., Bussiere, L. F., Jennions, M. D., \& Hunt, J. (2004). Sinister Strategies Succeed at the Cricket World Cup. Proceedings of the Royal Society of London B: Biological Sciences, 271, 64-66. https://doi.org/10.1098/rsbl.2003.0100

Coon, D., \& Mitterer, J. O. (2011). Psychology: Modules for Active Learning with Concept Modules with Note-Taking and Practice Exams. CA: Wadsworth.

Coon, D., \& Mitterer, J. O. (2009). Psychology: Modules for Active Learning (11th ed.) CA: Wadsworth.

Donaldson, G., \& Johnson, G. (2006). The Clinical Relevance of Hand Preference and Laterality. Physical Therapy Reviews, 11, 195-203. https://doi.org/10.1179/108331906X99074

Eckner, J. T., Kutcher, J. S., \& Richardson, J. K. (2010). Pilot Evaluation of a Novel Clinical Test of Reaction Time in National Collegiate Athletic Association Division Football Players. Journal of Athletic Training, 45, 327-332.

https://doi.org/10.4085/1062-6050-45.4.327

Faurie, C., \& Raymond, N. (2005). Handedness, Homicide, and Negative Frequency-Dependent Selection. Proceedings of the Royal Society of London B: Biological Sciences, 272, 25-28. https://doi.org/10.1098/rspb.2004.2926

Fisekcioglu, B. İ. (2011). Relations of Hand Preference, Muscle Power, Lung Function and Reaction Time in Right-Handed Taekwondo Players. World Applied Sciences Journal, 12, 1288-1290.

Geschwin, N., \& Behan, P. (1982). Left-Handedness: Association with İmmune Disease, Migraine, and Developmental Learning Disorder. Proceedings of the National Academy of Sciences, 79, 5097-5100. https://doi.org/10.1073/pnas.79.16.5097

Geshwind, N., \& Galburda, A. M. (1985). Cerebral Lateralization: Biological Mechanism, Associations and Pathology: A Hypothesis and a Program for Research. Archives of Neurology, 42, 428-459. https://doi.org/10.1001/archneur.1985.04060050026008

Gursoy, R. (2009). Effects of Left- or Right-Hand Preference on the Success of Boxers in Turkey. British Journal of Sports Medicine, 43, 142-144. https://doi.org/10.1136/bjsm.2007.043547

Holtzen, D. W. (2000). Handedness and Professional Tennis. International Journal Neuroscience, 105, 101-119. https://doi.org/10.3109/00207450009003270

Jones, L. F., Classe, J. G., Hester, M., \& Harris, K. (1996). Association between Eye Dominance and Training for Rifle Marksmanship: A Pilot Study. Journal of the American Optometric Association, 67, 73-76.

Lanzoni, I. M., Semprini, G., Di Michele, R., \& Merni, F. (2013). Top Athletes Handedness in the Major Racket Sports. In The 13th ITTF Sport Science Congress (pp. 160-163).

Loffing, F., Hagemann, N., \& Strauss, B. (2010). Automated Processes in Tennis: Do Left-Handed Players Benefit from the Tactical Preferences of Their Opponents? Journal of Sports Sciences, 28, 435-443.

Loffing, F., Hagemann, N., \& Strauss, B. (2012). Left-Handedness in Professional and Amateur Tennis. PLoS ONE, 7, e49325. https://doi.org/10.1371/journal.pone.0049325

Nass, R. D., \& Gazzaniga, M. S. (1987). Cerebral Lateralization and Specializat İon in Human Central Nervous System. In F. Plum (Ed.), Handbook of Physiology (pp. 701-761). Bethesda: The American Physiological Society. 
Oldfield, R. C. (1971). The Assesment and Analysis of Handedness: The Edinburg Inventory. Neuropsychologia, 9, 97-113.

Peters, M. (2004). La lateralite manuelle chez les adultes: Dans quelle mesure la main non preferee peut-elle atteindre les capacites de la main preferee? [Hand Laterality in Adults: To what Extent Can the Unpreferred Hand Reach the Capacities of the Preferred Hand?] Marseille: Solal.

Porac, C., \& Coren, S. (1981). Lateral Preferences in Human Behavior. New York, NY: Springer-Verlay. https://doi.org/10.1007/978-1-4613-8139-6

Raymond, M., Pontier, D., Dufour, A. B., \& Moller, A. P. (1996). Frequency Dependent Maintenance of Left-Handedness in Humans. Proceedings of the Royal Society of London B: Biological Sciences, 263, 1627-1633. https://doi.org/10.1098/rspb.1996.0238

Shereran, T. J. (1985). Effect of Pure and Crossed Dextrality on Marksmanship Skill. Perceptual and Motor Skills, 61, 1171-1174. https://doi.org/10.2466/pms.1985.61.3f.1171

Shorer, J., Loffing, F., Hagemann, N., \& Baker, J. (2012). Human Handedness in Interactive Situations: Negative Perceptual Frequency Effects Can Be Reversed. Journal of Sport Sciences, 30, 507-513. https://doi.org/10.1080/02640414.2012.654811

Simon, F. (1998). Les capacites physiques et motrices specifiques. In Le tir a L'arc-comprendre, pratiquer, enseigner. [Specific Physical and Motor Capacities. In the Shooting a the Arc-Comprise, to Practice, to Teach.] Paris: INSEP.

Steele, J., \& Uomini, N. T. (2005). Humans, Tools and Handedness. In V. Roux, \& B. Bril (Eds.), Stone Knapping: The Necessary Conditions for a Uniquely Hominine Behaviour (pp. 217-239). Cambridge: McDonald Institute for Archaeological Research.

Sylvain, L., \& Fabrice, E. M. (2009). Dosseville Interaction of Hand Preference with Eye Dominance on Accuracy in Archery. Perceptual and Motor Skills, 108, 558-564. https://doi.org/10.2466/pms.108.2.558-564

Wood, C. J., \& Aggleton, J. P. (1989). Handedness in “Fast Ball” Sports: Do Left-Handers Have an İnnate Advantage? British Journal of Psychology, 80, 227-240.

Ziyagil, M. A., Gursoy, R. et al. (2010). Left-Handed Wrestlers Are More Successful. Perceptual and Motor Skills, 111, 65-70.

https://doi.org/10.2466/04.05.19.25.PMS.111.4.65-70 